Virginia Commonwealth University vCU Scholars Compass

2014

\title{
Orientation-dependent pseudomorphic growth of InAs for use in lattice-mismatched mid-infrared photonic structures
}

Gregory Edward Triplett

Virginia Commonwealth University, getriplett@vcu.edu

Charles Meyer

Emily Cheng

Follow this and additional works at: https://scholarscompass.vcu.edu/egre_pubs

Part of the Electronic Devices and Semiconductor Manufacturing Commons, Process Control and Systems Commons, and the Semiconductor and Optical Materials Commons

(C) American Vacuum Society

\section{Downloaded from}

https://scholarscompass.vcu.edu/egre_pubs/210

This Article is brought to you for free and open access by the Dept. of Electrical and Computer Engineering at VCU Scholars Compass. It has been accepted for inclusion in Electrical and Computer Engineering Publications by an authorized administrator of VCU Scholars Compass. For more information, please contact libcompass@vcu.edu. 


\section{Orientation-dependent pseudomorphic growth of InAs for use in lattice-mismatched mid-infrared photonic structures}

Charles Meyer, Emily Cheng, and Gregory Triplett

Citation: Journal of Vacuum Science \& Technology B 32, 02C118 (2014); doi: 10.1116/1.4867879

View online: https://doi.org/10.1116/1.4867879

View Table of Contents: http://avs.scitation.org/toc/jvb/32/2

Published by the American Vacuum Society

\section{Articles you may be interested in}

Pseudomorphic growth of InAs on misoriented GaAs for extending quantum cascade laser wavelength Journal of Vacuum Science \& Technology A: Vacuum, Surfaces, and Films 31, 06F109 (2013);

$10.1116 / 1.4828357$

Reduced auger recombination in mid-infrared semiconductor lasers

Journal of Applied Physics 110, 073108 (2011); 10.1063/1.3646552

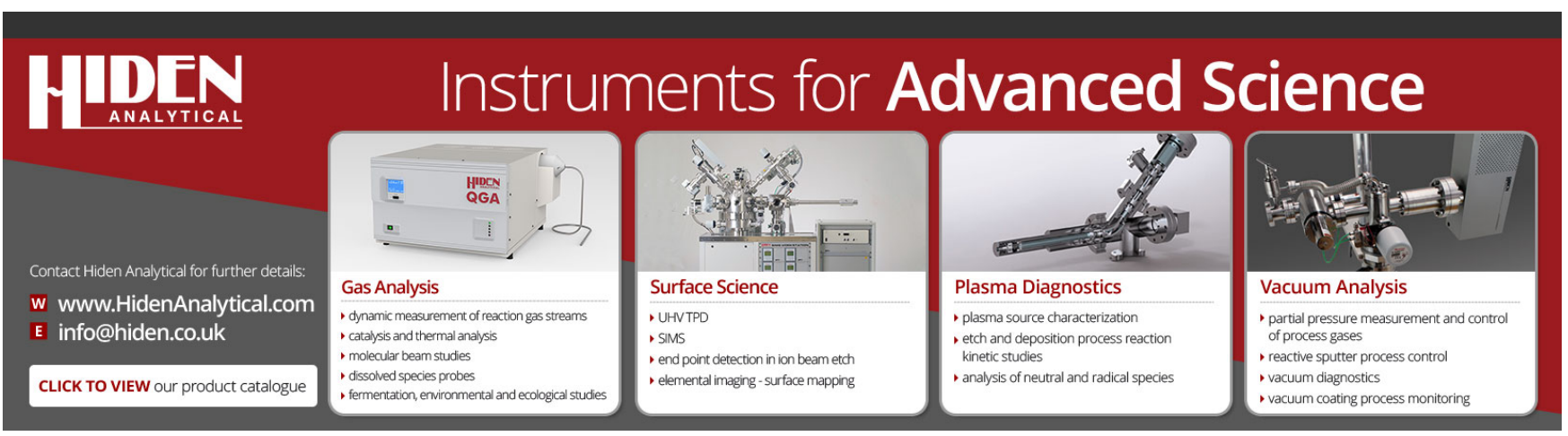




\title{
Orientation-dependent pseudomorphic growth of InAs for use in lattice-mismatched mid-infrared photonic structures
}

\author{
Charles Meyer, Emily Cheng, and Gregory Triplett ${ }^{\mathrm{a})}$ \\ Department of Electrical and Computer Engineering, University of Missouri-Columbia, \\ 349 Engineering Building West, Columbia, Missouri 65211
}

(Received 12 November 2013; accepted 25 February 2014; published 10 March 2014)

\begin{abstract}
In this study, InAs was deposited on GaAs (100) and GaAs (111)B $2^{\circ} \rightarrow\langle 2-1-1\rangle$ substrates for the purpose of differentiating the InAs growth mode stemming from strain and then analyzed using in-situ reflection high energy electron diffraction, scanning electron microscopy, Raman spectroscopy, reflectance spectroscopy, and atomic force microscopy. The procession of InAs deposition throughout a range of deposition conditions results in assorted forms of strain relief revealing that, despite lattice mismatch for InAs on GaAs (approximately 7\%), InAs does not necessarily result in typical quantum dot/wire formation on (111) surfaces, but instead proceeds two-dimensionally due primarily to the surface orientation. (c) 2014 American Vacuum Society. [http://dx.doi.org/10.1116/1.4867879]
\end{abstract}

\section{INTRODUCTION}

Indium arsenide (InAs) semiconductor devices that operate in the mid-infrared region are of interest, particularly for applications that include environmental monitoring, infrared countermeasures, thermal imaging, as well as free space communications. ${ }^{1}$ InAs remains an attractive semiconductor material for its inherent properties (e.g., electron affinity, carrier transport, low deposition temperature) when incorporated with other materials systems. ${ }^{2}$ The interest of this study is to explore the products of strain relief in InAs epilayers that are attributed to the difference in lattice constants $(\mathrm{GaAs}=5.65 \AA$ and $\operatorname{InAs}=6.06 \AA$ ) and orientation. Typically, InAs deposited on smaller lattice constant materials results in threedimensional features (i.e., quantum dots and wires) due to the compressive strain. ${ }^{3,4}$ However, InAs growth on GaAs (111)B $2^{\circ} \rightarrow\langle 2-1-1\rangle$ has revealed the possibility of pseudomorphic, layer-by-layer InAs formation despite the $\sim 7 \%$ lattice mismatch, which opens up extraordinary possibilities to extend the performance of mid-infrared systems. ${ }^{5}$

Realizing strain relief mechanisms in InAs-based latticemismatched heterostructures is important for creating efficient, defect-free photonic devices. In fact, taking advantage of the large conduction band offset $\left(\Delta \mathrm{E}_{\mathrm{c}}\right)$ between InAs on GaAs provides a unique opportunity to construct novel intersubband structures that allow nonlinear optical processes. ${ }^{6}$ Overcoming compressive strain issues in these systems is the key to producing photonic devices with expanded power delivering capabilities in the mid-infrared region of the electromagnetic spectrum, thus meeting new demands for sensing and communications applications. ${ }^{7-9}$ Interestingly, the inherent electric fields in strained InAs-based structures present another degree of freedom for bandgap-engineered laser structures, where the intersubband separation can be extended. ${ }^{10}$ In this work, thin InAs structures deposited on GaAs (111)B $2^{\circ} \rightarrow\langle 2-1-1\rangle$ have demonstrated a distinctly different growth mode than that observed with GaAs (100). As a result, the induced electric field (due to the piezoelectric

$\overline{{ }^{a)} \text { Electronic mail:triplettg@missouri.edu }}$ effect) may be taken advantage of to open up a new design space for this important material system.

The ideal conditions for producing optical quality InAsbased heterostructures on (100) and (111) surfaces are uniquely different. For instance, the deposition window for (111) substrates is comparatively narrower than the deposition window for (100) surfaces. ${ }^{11}$ As presented in previous reports, the various molecular beam epitaxy process ranges for arsenic-based materials, resulting in good structural and electrical properties have been found to require lower arsenic overpressure along with higher growth temperature, which also depends on the orientation angle of the (111) substrate. ${ }^{12,13}$ These process conditions are, in fact, contrary to those conditions typically employed for material deposition on (100) surfaces. In a study by Marcadet et al. ${ }^{13}$ GaAs step flow growth on (111) GaAs by molecular beam epitaxy was examined to obtain mirrorlike surfaces. The governing molecular beam epitaxy parameters were substrate temperature and (arsenic to gallium) flux ratio. Results show that surface morphology was governed by substrate orientation angle, where lower orientation $\left(0.5^{\circ}\right)$ has a higher growth temperature limit and higher orientation $\left(2^{\circ}\right)$ has a lower temperature limit. The difference in substrate temperature according to substrate orientation actually modifies the Ga adatom surface diffusion length, which directly influences film morphology. This slight divergence from preferred (100) surface process conditions has a direct impact on the ability to synthesize strained $\operatorname{In}(\mathrm{Ga})$ As layers on (111). In regards to the piezoelectric properties, Cho et al. ${ }^{14}$ studied the interfaces of strained $\operatorname{In}(\mathrm{Ga})$ As structures on (111) GaAs substrates. Results show that not only are atomically smoother interfaces possible for highly strained piezoelectric $\operatorname{In}(\mathrm{Ga}) \mathrm{As} / \mathrm{GaAs}$

\begin{tabular}{|c|}
\hline InAs (17 Monolayers, $~ 7 \%$ Lattice Mismatch) \\
\hline 100nm GaAs Buffer Layer \\
\hline GaAs (111)B $2^{\circ} \rightarrow<2-1-1>$ Substrate \\
\hline
\end{tabular}

FIG. 1. GaAs/InAs heterostructure shown was deposited under varied process conditions. 
TABLE I. Sample growth conditions.

\begin{tabular}{lcccc}
\hline \hline Sample & V:III ratio & $\begin{array}{c}\text { Substrate } \\
\text { temperature }\left({ }^{\circ} \mathrm{C}\right)\end{array}$ & $\begin{array}{c}\text { Deposition } \\
\text { rate }(\mu \mathrm{m} / \mathrm{h})\end{array}$ & $\begin{array}{c}\text { RMS } \\
\text { roughness }(\mathrm{nm})\end{array}$ \\
\hline (a) & $10: 1$ & 480 & 0.039 & 0.97 \\
(b) & $20: 1$ & 480 & 0.039 & 0.92 \\
(c) & $20: 1$ & 500 & 0.039 & 0.23 \\
(d) & $20: 1$ & 480 & 0.101 & 1.13 \\
(e) & $30: 1$ & 480 & 0.101 & 1.22 \\
(f) & $40: 1$ & 480 & 0.101 & 1.27 \\
\hline
\end{tabular}

quantum wells, but also the longitudinal-optical phonon energy $(\sim 37 \mathrm{meV})$ is comparable with strained InGaAs wells grown on (100) surfaces. From a photonic device point of view, the similarities in longitudinal-optical phonon energies are encouraging since this is the primary mechanism for the depopulation of lower energy states in intersubband laser structures. However, substrate growth temperature (which controls adatom surface diffusion length) is clearly a governing parameter for smooth epitaxial films on (111). With stringent control of molecular beam epitaxy process parameters and greater understanding of the strain relief mechanisms, excellent material quality for strained structures can be obtained. ${ }^{15}$ Therefore, molecular beam epitaxy conditions are explored for the production of high-quality strained InAs-based epilayers on various surfaces.

\section{EXPERIMENT}

Seventeen-monolayer-thick InAs structures (Fig. 1) were deposited simultaneously on GaAs (100) as well as (111)B $2^{\circ} \rightarrow\langle 2-1-1\rangle$ substrates in a 3 in. solid-source molecular

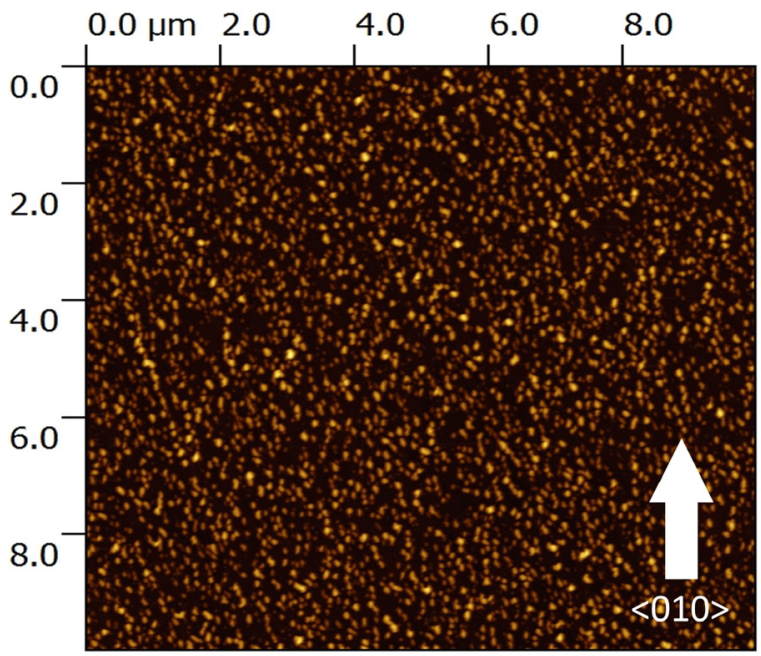

FIG. 2. (Color online) $10 \mu \mathrm{m} \times 10 \mu \mathrm{m}$ AFM scan of the InAs structure on the GaAs (100) substrate. The root mean square roughness was $1.73 \mathrm{~nm}$.

beam epitaxy reactor under a variety of process conditions (Table I). Arsenic overpressure was provided by a valvedcracker where the bulk zone was $360{ }^{\circ} \mathrm{C}$ and cracker zone was $600^{\circ} \mathrm{C}$, while gallium and indium beam fluxes were provided by dual-temperature zone thermal effusion cells at select temperatures. The source and substrate panels were cooled with flowing liquid nitrogen and the chamber pressure was maintained at a base pressure on the order of $10^{-9}$ Torr. The (100) and (111)B $2^{\circ} \rightarrow\langle 2-1-1\rangle$ substrates were cleaved and indium-mounted side-by-side on molybdenum blocks and exposed to the same reactor conditions throughout the experiment. RHEED analysis (using a 12-bit CCD camera with a $15-\mathrm{kV}$ Staib Instruments electron gun)

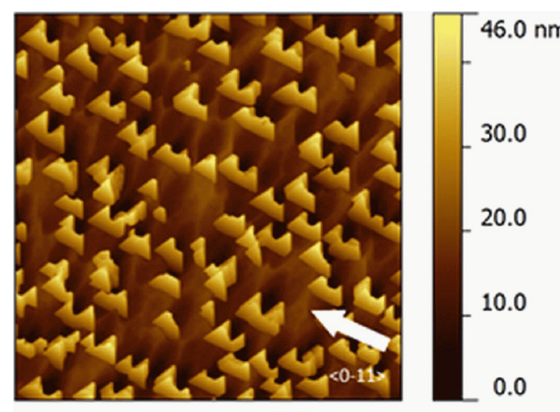

(a)

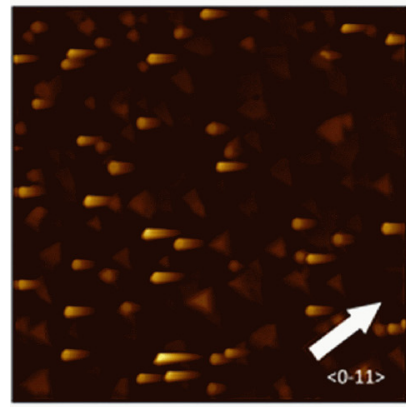

(d)

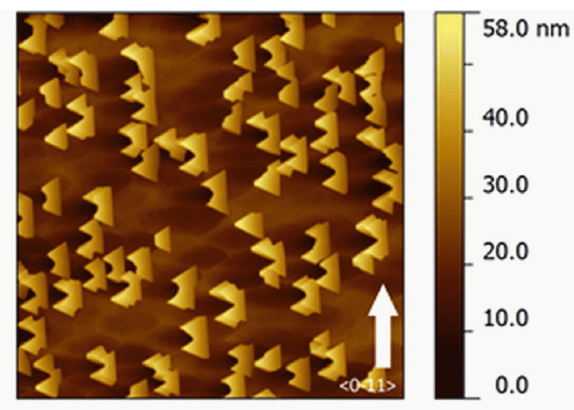

(b)

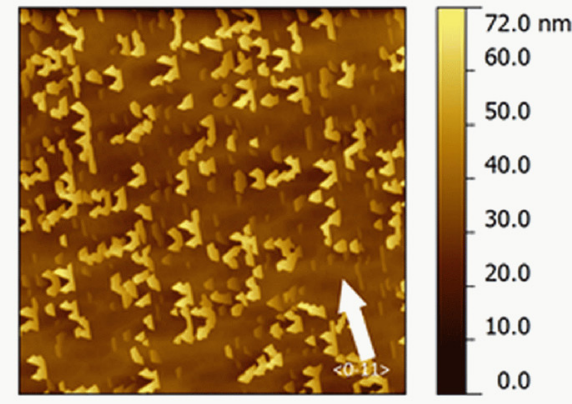

(e)

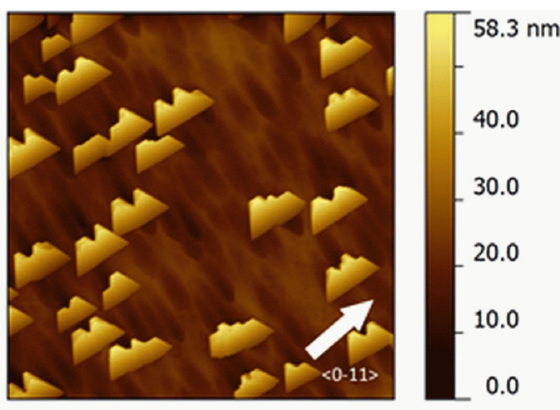

(c)

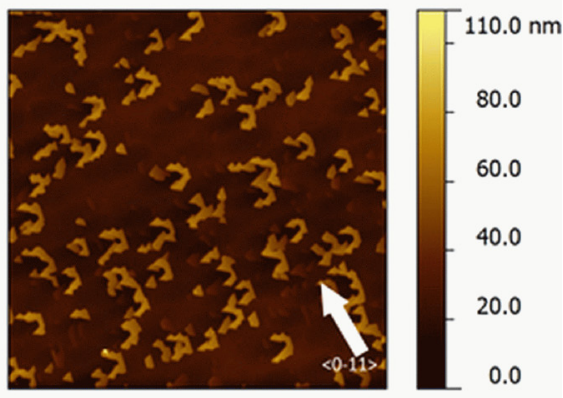

(f)

FIg. 3. (Color online) $10 \mu \mathrm{m} \times 10 \mu \mathrm{m}$ AFM images of the InAs/GaAs structures on the GaAs $(111) \mathrm{B} 2^{\circ} \rightarrow\langle 2-1-1\rangle$ plane. The $\langle 0-11\rangle$ direction is labeled for each scan. Sample labels correspond with the process conditions listed in Table I. 


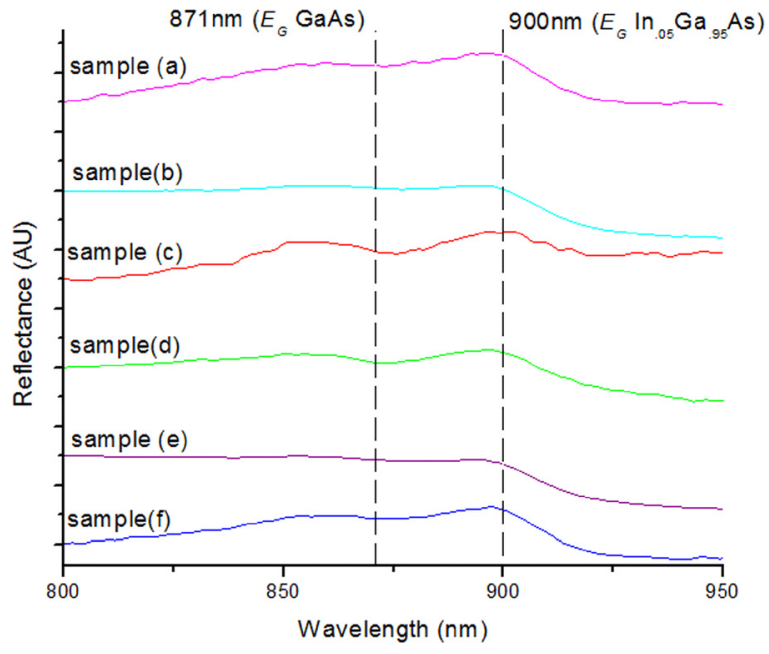

FIG. 4. (Color online) Reflectance spectra for each sample. With decreasing InAs surface coverage, the reflectance decrease associated with GaAs at $871 \mathrm{~nm}$ becomes more pronounced.

was employed on the (100) surface to confirm oxide desorption, determine deposition rate, and monitor deposition of the epitaxial layers. The substrates were continuously rotated throughout epitaxy, except during deposition rate determination.

During the deposition process, after the protective oxide layer was thermally desorbed from GaAs at approximately $580^{\circ} \mathrm{C}$, a $100 \mathrm{~nm}$ GaAs smoothing layer was deposited before growth of the InAs layer commenced. The RHEED pattern at the end of the smoothing layer showed a streaky $(2 \times 4)$ reconstruction. Following sample growth, each wafer was analyzed using an Agilent Technologies 5500 AFM in $10 \mu \mathrm{m} \times 10 \mu \mathrm{m}$ scans, an FEI Quanta 600 FEG extended vacuum scanning electron microscope, and a Raman microscopy system. Each surface was also measured for roomtemperature reflectance using a broadband IR source. The SEM data were used primarily for qualitative confirmation of smooth epitaxial layers and large area analysis. AFM data were imported into the Gwyddion ${ }^{16}$ software package, and quantitative surface roughness parameters were measured, including average roughness, root mean square roughness, average maximum roughness height, etc. These roughness data were subsequently modeled using analysis of variance to determine the most significant process conditions for depositing smooth InAs layers on GaAs (111)B $2^{\circ} \rightarrow\langle 2-1$ $1\rangle$. Reflectance data were used to demonstrate surface coverage, and the Raman data were used to map the InAs quantum island formation across each wafer.

\section{RESULTS AND DISCUSSION}

AFM analysis of InAs deposited on various surfaces highlight the dependence of surface roughness on substrate orientation. The AFM roughness model (with a 0.95 confidence level) demonstrated empirical relationships between surface roughness and molecular beam epitaxy process conditions, where the smoothest InAs layers were produced on (111)B $2^{\circ} \rightarrow\langle 2-1-1\rangle$ plane with an average surface roughness

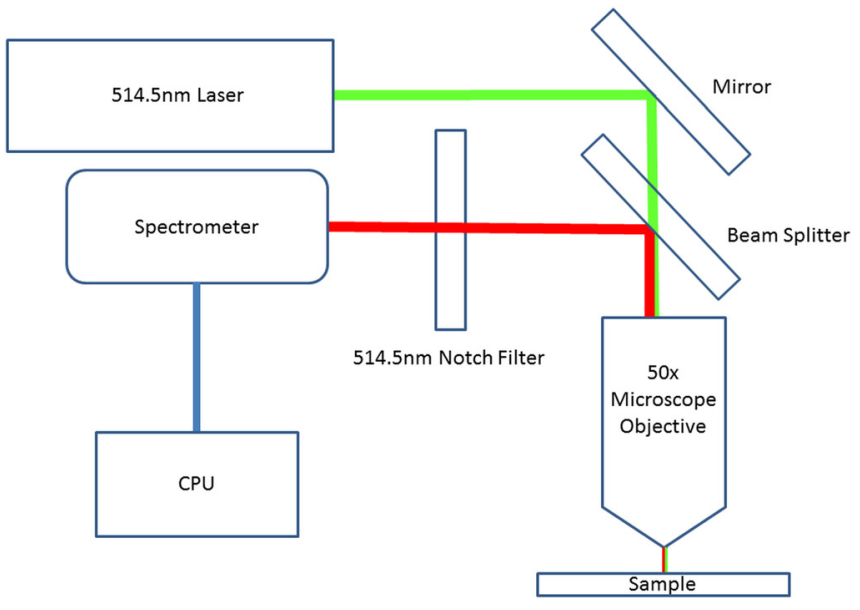

FIG. 5. (Color online) Raman measurement system in backscattering configuration.

around $0.23 \mathrm{~nm}$. The smoothest samples with the most uniform InAs coverage were produced with a deposition rate of $0.039 \mu \mathrm{m} / \mathrm{h}$ and at a substrate temperature of $480{ }^{\circ} \mathrm{C}$. For all samples produced, slower deposition rates created a more favorable environment for pseudomorphic growth, which is likely associated with improved adatom diffusion length. In this parameter study, InAs-on-GaAs thin films produced on (100) orientation reveal a commonly observed selforganized quantum dot formation (Fig. 2). Regardless of InAs layer thickness, Stranski-Krastanow (SK) growth modes proceed on the lattice-mismatched substrate via formation of three-dimensional islands (after growth of the wetting layer). In contrast to the RHEED pattern observed for smooth growth, the island (dot) growth transformed the streaky RHEED $(2 \times 4)$ pattern to a spotty pattern, which is common for three-dimensional islands on the growth surface. These samples produced islands and areal densities that conform to the pyramid-like shape and $10^{8}$ and $10^{11} / \mathrm{cm}^{2}$ values, as reported by others. ${ }^{17}$ For GaAs (111) samples

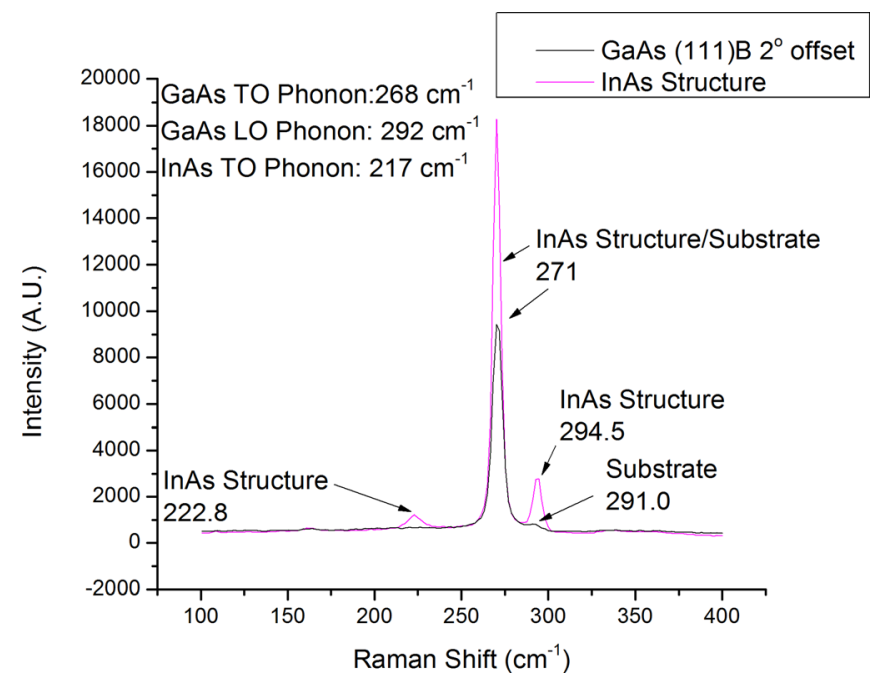

FIG. 6. (Color online) Raman shifts of both the plain GaAs (111)B $2^{\circ} \rightarrow\langle 2-1-1\rangle$ substrate and the InAs/GaAs strained heterostructure are shown. The strained structure shows an increase in Raman intensity, as well as a peak that corresponds to the InAs TO phonon. 

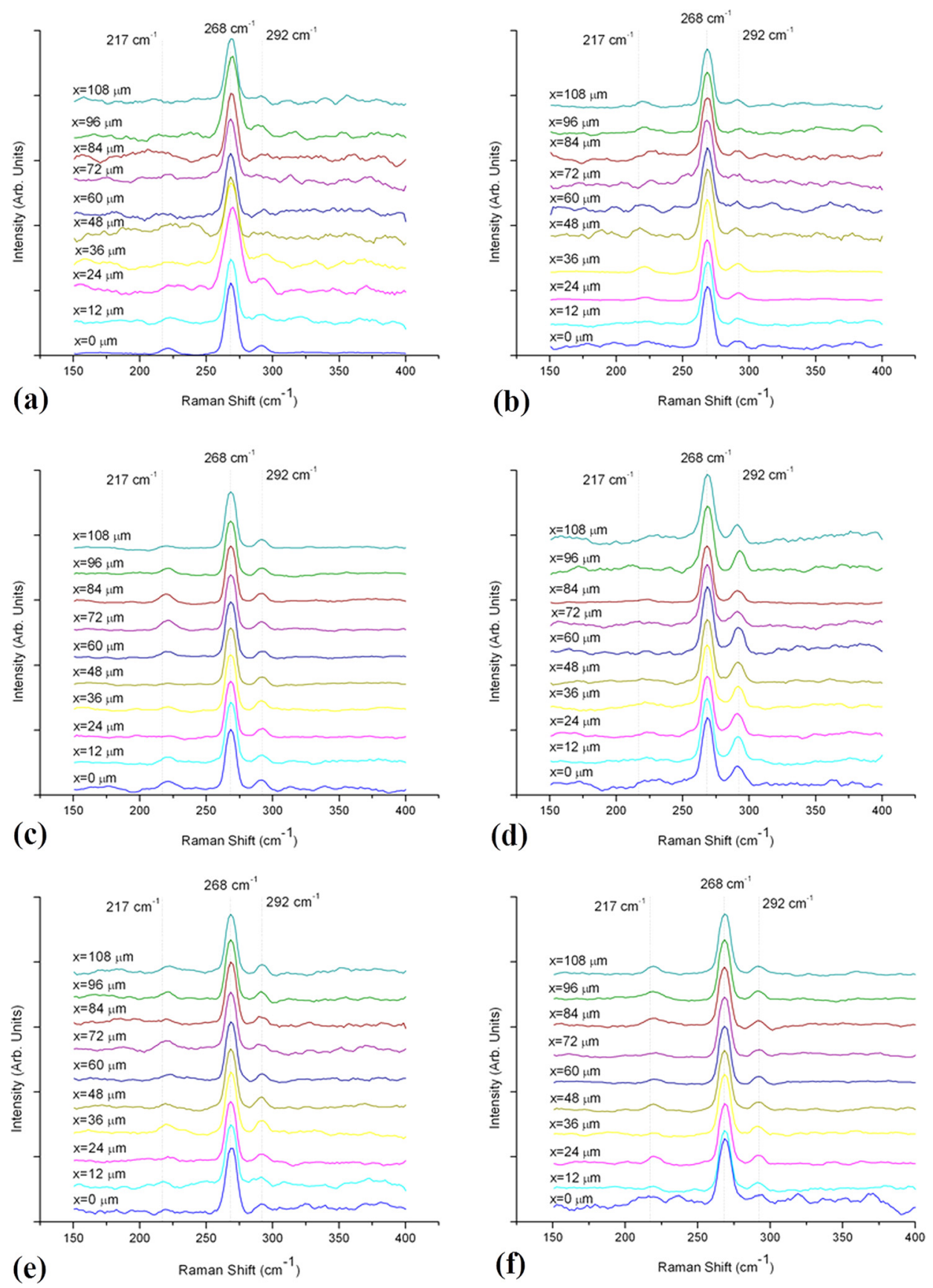

FIG. 7. (Color online) Raman intensity maps over a $108 \mu \mathrm{m}$ distance of each sample. InAs structures are denoted by the increase in Raman intensity at $217 \mathrm{~cm}^{-1}$.

oriented along the $\langle 0-11\rangle$ direction, the growth modes proceeds differently than GaAs (100) surfaces. The deposition commences in a Volmer-Weber mode, where adatoms find an opportune nucleation site and continue in a layer-by-layer fashion from that nucleation point. Depending on the process conditions (most notably substrate temperature and anion overpressure), an increased plateau size as the growth proceeds was observed (Fig. 3).

Reflectivity measurements also confirm surface coverage for each InAs sample. For samples with minimal InAs epilayer coverage, the reflectance of the GaAs (111)B $2^{\circ} \rightarrow\langle 2-1-1\rangle$ substrate dominates (Fig. 3). For example, sample (c) has less InAs coverage, as illustrated via AFM in Fig. 4. The dip in reflectance is clear at $871 \mathrm{~nm}$ for this sample, corresponding with the large surface area of the substrate that is not covered by the epilayer. Sample (e), on the other hand, has more complete InAs coverage. Therefore, the dip associated with $E_{G}$ for the GaAs substrate at $871 \mathrm{~nm}$ is far less pronounced on this sample. The drop in reflectance at $900 \mathrm{~nm}$ corresponds with intermixing of the InAs and GaAs reflectance signals.

Raman shifts associated with the thin InAs-based heterostructures were also measured using the backscattering technique (Fig. 5) and the results are shown in Fig. 6. Raman shifts correspond to known vibrational frequencies for chemical bonds; therefore, the absence or presence of Raman shifts associated with a chemical bond correlates with the 
absence or presence of that bond. For comparison, Raman shifts of the GaAs (111)B $2^{\circ} \rightarrow\langle 2-1-1\rangle$ substrate are also shown. Peaks due to the InAs transverse optical (TO) phonon can be seen at approximately $217 \mathrm{~cm}^{-1}$, which demonstrates the quality of these experiments. The InAs heterostructures that were produced enhanced the intensity of both the longitudinal optical phonon and the transverse optical phonon for GaAs, located at approximately $292 \mathrm{~cm}^{-1}$ and $268 \mathrm{~cm}^{-1}$, respectively. ${ }^{18}$ The actual Raman shift for all of these phonons increased very slightly.

To further measure InAs coverage over the GaAs (111)B $2^{\circ} \rightarrow\langle 2-1-1\rangle$ surface, several Raman scans were repeated at $12 \mu \mathrm{m}$ intervals across a $108 \mu \mathrm{m}$ distance of each sample (Fig. 7). In agreement with Fig. 6, the InAs TO phonon is visible near $217 \mathrm{~cm}^{-1}$ and the Raman shift intensifies at $271 \mathrm{~cm}^{-1}$ and $\sim 291 \mathrm{~cm}^{-1}$ for areas covered by InAs. Lower intensity Raman shifts attributed to GaAs (111)B $2^{\circ} \rightarrow\langle 2-1-1\rangle$ are present for areas not fully covered by the InAs epilayer. The Raman maps show the spacing and quality of the InAs epilayer. For example, sample (d) had poor surface topography, and the InAs TO phonon shows very weak intensity across the wafer.

In the InAs structure, biaxial strain is induced due to the large lattice mismatch $(\sim 7 \%)$ between the InAs and GaAs substrate. This strain could account for the slight shift in phonon energies from ideal values. The measured InAs TO phonon is $222.8 \mathrm{~cm}^{-1}$ as opposed to the bulk value of $217 \mathrm{~cm}^{-1}$. This gives a deviation of $2.7 \%$. According to Yang et al., ${ }^{19}$ the expected relationship between this deviation and the perpendicular strain component as a result of the lattice mismatch is given by $(0.86 \pm 0.03) \varepsilon_{\perp}$, where $\varepsilon_{\perp}$ is the perpendicular strain component. Using this relationship, the expected deviation should be approximately $6.7 \%$, where the $\varepsilon_{\perp}$ is $-7.86 \%$ and ell is $+7.23 \%$. The extracted lattice constant of the InAs layer is then $\sim 5.9 \AA$, where the average indium content is $64 \%$. Since the Raman data suggests some relaxation did occur due to lattice mismatch, it seems plausible even for most GaAs substrate orientations. In contrast, AFM data confirms the formation of two-dimensional-like features. Since the expected deviation is not evident and full InAs coverage is not routinely accomplished for small thicknesses, presumably some pseudomorphic growth has occurred, despite the large lattice mismatch.

\section{SUMMARY AND CONCLUSIONS}

The deposition of InAs on GaAs (100) and GaAs (111)B $2^{\circ} \rightarrow\langle 2-1-1\rangle$ substrates and orientations has been analyzed using SEM, AFM, and Raman spectroscopy. Depending on the process conditions, the InAs growth can follow a twodimensional, pseudomorphic growth pattern on (111)B with $2^{\circ}$ offset toward $\langle 2-1-1\rangle$, despite the $7 \%$ lattice mismatch. The empirical surface roughness model reveals that surface orientation and molecular beam process conditions significantly affect morphology. Limitation of adatom diffusion length during deposition via the substrate temperature, arsenic overpressure, and low deposition rate appears to be the critical factors for creating smooth, defect-free epitaxial InAs layers on GaAs (111)B $2^{\circ}$ offset toward $\langle 2-1-1\rangle$. Control of the diffusion length for indium species is therefore critical for creating optical quality structures on GaAs (111)B with $2^{\circ}$ offset toward $\langle 2-1-1\rangle$ substrates.

\section{ACKNOWLEDGMENT}

This work was supported by AFOSR Young Investigator Program Grant Number FA9550-10-1-0482.

${ }^{1}$ F. Capasso et al., IEEE J. Quantum Electron. 38, 511 (2002).

${ }^{2}$ S. E. Hooper, Semicond. Sci. Technol. 8, 1069 (1993).

${ }^{3}$ L. Goldstein, F. Glas, J. Marzin, M. Charasse, and G. Le Roux, Appl. Phys. Lett. 47, 1099 (1985).

${ }^{4}$ M. Grundmann, O. Stier, and D. Bimberg, Phys. Rev. B 52, 11969 (1995). ${ }^{5}$ D. Mueller, D. Roberts, and G. Triplett, J. Electron. Mater. 41, 959 (2012).

${ }^{6}$ G. Triplett and D. Roberts, IEEE J. Quantum Electron. 46, 1782 (2010).

${ }^{7}$ F. K. Tittel, D. Richter, and A. Fried, in Solid-State Mid-Infrared Laser Sources (Springer, New York, 2003), pp. 458-529.

${ }^{8}$ P. Werle, F. Slemr, K. Maurer, R. Kormann, R. Mücke, and B. Jänker, Opt. Laser. Eng. 37, 101 (2002).

${ }^{9}$ C. H. Chan, M. C. Chen, H. H. Lin, Y. F. Chen, G. J. Jan, and Y. H. Chen, Appl. Phys. Lett. 72, 1208 (1998).

${ }^{10}$ B. Laurich, K. Elcess, C. Fonstad, J. Beery, C. Mailhiot, and D. Smith, Phys. Rev. Lett. 62, 649 (1989).

${ }^{11}$ W. Yeo, R. Dimitrov, W. J. Schaff, and L. F. Eastman, Appl. Phys. Lett. 77, 2764 (2000).

${ }^{12}$ T. Hayakawa, M. Morishima, and S. Chen, Appl. Phys. Lett. 59, 3321 (1991).

${ }^{13}$ X. Marcadet, J. Olivier and J. Nagle, Proceedings of the Sixth International Conference on the Formation of Semiconductor Interfaces (British Assoc. Crystal Growth, British Tourist Authority, IOP, Cardiff, UK, 1997).

${ }^{14}$ S. Cho, A. Sanz-Hervás, J. Kim, A. Majerfeld, and B. W. Kim, J. Appl. Phys. 96, 1909 (2004).

${ }^{15}$ X. Marcadet, V. Ortiz, J. Y. Bengloan, S. Dhillon, M. Calligaro, and C. Sirtori, J. Vac. Sci. Technol. B 22, 1558 (2004).

${ }^{16}$ D. Nečas and P. Klapetek, Cent. Eur. J. Phys. 10, 181 (2012).

${ }^{17}$ D. Leonard, M. Krishnamurthy, C. M. Reaves, S. P. Denbaars, and P. M. Petroff, Appl. Phys. Lett. 63, 3203 (1993).

${ }^{18}$ D. J. Lockwood, G. Yu, and N. L. Rowell, Solid State Commun. 136, 404 (2005).

${ }^{19}$ M. J. Yang, R. J. Wagner, B. V. Shanabrook, W. J. Moore, J. R. Waterman, Ch. H. Yang, and M. Fatemi, Appl. Phys. Lett. 63, 3434 (1993). 